\title{
Guest editorial for the Special Issue on Design Theory
}

\author{
Dane L. Flannery • Kathryn J. Horadam
}

Published online: 26 June 2010

(C) Springer Science+Business Media, LLC 2010

This Special Issue on Design Theory contains a wide range of papers with high relevance to the scope of Cryptography and Communications: Discrete Structures, Boolean Functions and Sequences. The designs of interest all fall into the category of pairwise balanced designs, where typically pairs of distinct rows of an array satisfy some balance condition such as orthogonality. Of central interest are the Hadamard matrices and their generalisations, which have extensive application in coding, cryptography and communications sequence design.

Beginning with a survey article on progress over the last three years in the focus area, the issue presents articles under the following three, increasingly specific, headings: pairwise balanced designs, complex Hadamard matrices, and Hadamard and cocyclic Hadamard matrices.

This volume honours Dr Warwick de Launey on the occasion of his 50th birthday. We are very fortunate indeed to count Warwick as our friend and collaborator. Here we are celebrating his many achievements in Design Theory, and Mathematics generally. Two significant contributions from Warwick and his co-authors appear in this collection.

Warwick was born in 1958 in Sydney, Australia. His undergraduate and PhD degrees are from The University of Sydney. His doctoral supervisor was Professor Jennifer Seberry, to whom Warwick credits his start in Mathematics, and who is also represented in this volume.

After working as a mathematician, and then Darwin Branch manager for the Australian mathematics and statistics consultancy SIROMATH, Warwick began his

D. L. Flannery $(\varangle)$

National University of Ireland, Galway, Ireland

e-mail: dane.flannery@nuigalway.ie

K. J. Horadam

RMIT University, GPO Box 2476, Melbourne, VIC 3001, Australia

e-mail: kathy.horadam@rmit.edu.au 
long association with Defence agencies. In 1989 he joined DSTO's Cryptomathematics Research Group in Melbourne. There he began a collaboration with the second editor, Kathy Horadam, from which sprang their discovery of cocyclic Hadamard matrices.

A posting to the USA led him to a permanent position with the Institute for Defense Analyses Center for Communications Research in California, where he has worked for 15 years. In this time Warwick has collaborated with many researchers over a broad range of disciplines. Warwick regards collaboration as the lifeblood of his research; as he says, "A major goal of my research in Design Theory has been to enrich Design Theory by drawing on applicable outside mathematical techniques and engaging their expert exponents in active research in Design Theory." Some of his collaborators (K.T. Arasu, John Dillon, Daniel Gordon, Hadi Kharaghani, David Levin, Richard Stafford) or their colleagues (Andreas Armario, Asha Rao) or students (Padraig Ó Catháin) are represented here.

Warwick's interests are eclectic and enthusiastic: his work in areas as diverse as analytic number theory, group theory and probability is reflected in the variety of his publications. But his enduring passion has been Design Theory, and his major effort in recent years has been the full formulation of his ideas arising from the definition of an orthogonality set and certain associated ambient rings, which can be used to frame a comprehensive algebraic study of the designs in question. His monograph on Algebraic Design Theory, co-authored with the first editor of this volume, Dane Flannery, is near completion.

One motivating event for this Special Issue was the 'International Conference on Design Theory and Applications' held in honour of Dr de Launey, at the National University of Ireland, Galway, in July 2009. A previous conference held in 2007 at Universidad de Sevilla, Spain, inaugurated what we hope will be a (more or less biennial) series of such conferences.

Many of the authors herein were speakers at the Galway conference. Warwick delivered the opening lecture. Despite a long and debilitating illness, he stood for 45 minutes describing his latest vision for Design Theory. His lecture concluded with an inspired discourse on the importance of courage and artistic creativity in mathematical research.

We are grateful to the de Brún Centre for Computational Algebra for logistical and financial support (via Science Foundation Ireland); and also to NUI Galway, and its Millennium Research Fund. We further acknowledge with deep gratitude the local assistance provided by Alla Detinko, Mary Kelly and Padraig Ó Catháin.

We thank Springer for approving this Special Issue. Particular mention must be made of Claude Carlet, Edward Sarmiento and Melissa Fearon, for their advice, assistance and patience throughout the process. Finally, our referees gave of their time and expertise cheerfully and generously (in several cases they went well beyond the normal refereeing duties and extended their authors' results). The resulting papers are a credit to all, and create a volume that truly honours our friend, Warwick de Launey.

\section{L. Flannery \\ K. J. Horadam \\ Guest Editors}

